\title{
Effective L/D: A Theoretical Approach to the Measurement of Aero-Structural Efficiency in Aircraft Design
}

\author{
Mark D. Guynn ${ }^{1}$ \\ NASA Langley Research Center, Hampton VA 23681, USA
}

\begin{abstract}
There are many trade-offs in aircraft design that ultimately impact the overall performance and characteristics of the final design. One well recognized and well understood trade-off is that of wing weight and aerodynamic efficiency. Higher aerodynamic efficiency can be obtained by increasing wing span, usually at the expense of higher wing weight. The proper balance of these two competing factors depends on the objectives of the design. For example, aerodynamic efficiency is preeminent for sailplanes and long slender wings result. Although the wing weight-drag trade is universally recognized, aerodynamic efficiency and structural efficiency are not usually considered in combination. This paper discusses the concept of "aero-structural efficiency," which combines weight and drag characteristics. A metric to quantify aero-structural efficiency, termed effective $L / D$, is then derived and tested with various scenarios. Effective $L / D$ is found to be a practical and robust means to simultaneously characterize aerodynamic and structural efficiency in the context of aircraft design. The primary value of the effective $L / D$ metric is as a means to better communicate the combined system level impacts of drag and structural weight.
\end{abstract}

\section{Nomenclature}

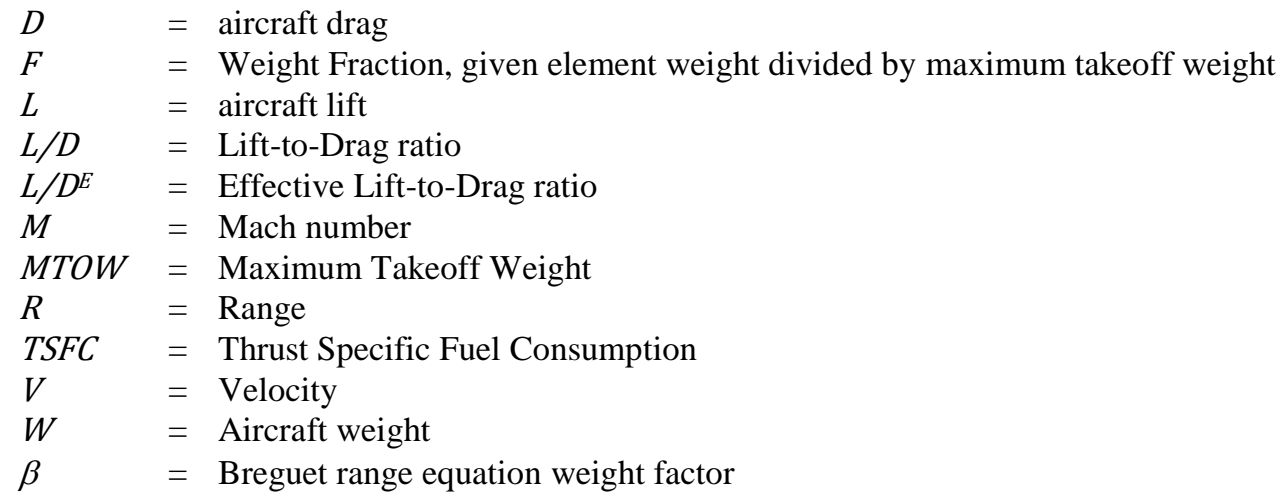

Subscripts:

start $=$ start-of-cruise

end $\quad=$ end-of-cruise

TO $=$ takeoff

fuel $=$ fuel

wing $=$ wing

pay $=$ payload

$O E W \quad=$ operating empty weight

\footnotetext{
${ }^{1}$ Aerospace Engineer, Aeronautical Systems Analysis Branch, Mail Stop 442, Senior Member AIAA.
} 


\section{Introduction}

$\mathrm{A}$ IRCRAFT design is a process of selecting the best combination of parameters in the presence of multiple tradeoffs and competing concerns. As the saying goes, "there is no free lunch." This is certainly true in aircraft design. It is usually possible to make the design better in one aspect, (for example, faster, more fuel efficient, lighter, or quieter) at the expense of another. The best design occurs when the appropriate balance of these competing factors is achieved, within the context of the vehicle's design requirements and objectives.

Although the potential design trade-offs are numerous, only a few key ones are typically investigated in the early stages of a vehicle's design. One example is the trade-off between engine efficiency and the increase in size and weight that occurs for higher bypass ratio engines. Selecting bypass ratio to maximize engine efficiency does not usually lead to the best aircraft design, because the engine weight and nacelle drag penalties offset the additional efficiency benefits. Another well recognized trade-off is the potential reduction in induced drag through higher wing span versus the resulting increase in wing weight. This can be generalized as a weight versus efficiency trade: how much added weight can be tolerated for a given efficiency improvement without the efficiency benefit being completely offset by the weight penalty?

Design interactions such as these can be approximately captured with "trade factors," which provide the designer the sensitivity of system-level performance to parameters such as engine efficiency, weight, and size. These trade factors enable the designer to make rational decisions about the design space without analysis of a complete, integrated system model. This is particularly useful in the context of engine design, for example, when the engine designer and the aircraft designer may work for separate companies and an integrated system model is not possible. Another approach to capturing design interactions is multi-disciplinary optimization. Assuming accurate model-based simulation and sufficiently robust optimization schemes, the optimization approach will lead to the best combination of design parameters to meet the designer's objective. Although automation of design trades through optimization offers many advantages, it does not always give the designer a clear picture of the relative sensitivities and underlying characteristics driving the design. This is especially problematic when technology development is a potential variable. Consider again the example of an ultra-high bypass ratio engine. The engine trade-offs, and resulting "best" bypass ratio, will be different if there is an option to develop a slim-line nacelle technology to mitigate the nacelle weight and drag penalties. Multi-disciplinary optimization alone would not answer the question of how aggressive does the slimline nacelle technology need to be to enable a net benefit for ultra-high bypass ratio.

The approach to characterizing design trades investigated in this paper is to develop a single parameter that encompasses both sides of the trade-off of interest. The trade-off investigated for this paper will be wing weight and aerodynamic efficiency. This "aero-structural efficiency" parameter enables quick comparison of multiple designs, with potentially different aerodynamic, materials, and structures technologies, to determine which design is "best." A simple theoretical construct is introduced and used to derive a quantitative metric for "aero-structural efficiency." A number of different test cases are then conducted to assess the robustness of the approach and potential shortcomings of the method are identified.

\section{Measurement of Aerodynamic Efficiency and Structural Efficiency}

Aerodynamic efficiency is often measured and compared in terms of lift divided by drag (L/D) or Mach number multiplied by L/D, (M.L/D). Even though this is an accepted and widely-used aerodynamic metric, it is far from perfect. One issue is that $\mathrm{L} / \mathrm{D}$ is not a unique characteristic, like Maximum Takeoff Weight $(M T O W)$ or wing span are; L/D can vary significantly throughout the course of a flight. For a meaningful comparison of L/D among aircraft, specific conditions at which it is measured must be specified (for example, takeoff, climb, mid-cruise, descent). Another issue is that comparing L/D can lead to erroneous conclusions when examined out of context. Higher L/D does not necessarily equate to "better." In fact, for a given aircraft a higher cruise weight can often lead to a higher cruise L/D, even though the drag is higher. In other words, higher L/D does not necessarily mean lower drag, which is the real goal of improving aerodynamic efficiency. The choice of L/D as a primary aerodynamic metric is likely because of its prominence in fundamental aeronautical relationships like the Breguet range equation. Derivation of this equation can be found in Ref. 1 .

$$
R=\frac{\left(V \cdot \frac{L}{D}\right)}{T S F C} \ln \left(\frac{W_{\text {start }}}{W_{\text {end }}}\right)
$$


where $R$ is range, $V$ is velocity, TSFC is thrust-specific fuel consumption, $W_{\text {start }}$ is the aircraft weight at the beginning of cruise and $W_{\text {end }}$ is the weight at the end of cruise.

Under the simplifying assumptions made to derive the Breguet range equation, aircraft range is directly proportional to the cruise L/D (or conversely, fuel required for a specified range is inversely proportional to L/D). While there is a simple relationship between L/D and fuel consumption for the ideal, theoretical case, it is not that simple for the real aircraft. The abstraction from the complex reality to the Breguet relationship and L/D as a measure of aerodynamic efficiency is, however, widely accepted in aircraft design.

There is not a metric for structural or weight efficiency that is as widely used as $\mathrm{L} / \mathrm{D}$ is for aerodynamic efficiency. Perhaps the most common metric is weight fraction, the weight of the structure or component divided by the MTOW of the aircraft. The Breguet range equation can be written in terms of weight fractions and weight fractions are used in a number of conceptual design sizing methodologies. The basic assumption in those methodologies is that weight fractions are relatively constant for a given type/class of vehicle. Conceptually, measuring wing weight efficiency with the wing weight fraction (wing weight divided by MTOW) seems appropriate since the heavier the aircraft the higher load the wing has to support, although the weight fraction implies a linear relationship. But, even more so than for $\mathrm{L} / \mathrm{D}$, there are extraneous factors which impact the weight fraction and lessen its attractiveness as a general structural efficiency metric. One issue with weight fractions is that the denominator (MTOW) is a function of the fuel efficiency of the aircraft, since it includes the fuel weight carried. Structural weight fractions, therefore, can increase as the result of increases in propulsion and aerodynamic efficiency. Conversely, a low structural weight fraction may simply be an indication of a very fuel inefficient vehicle (large fuel load), not an efficient structure. Despite these shortcomings, however, weight fraction is still a useful parameter that is often used to measure structural efficiency.

\section{Measurement of Aero-Structural Efficiency}

Although not perfect, reasonable metrics exist for aerodynamic efficiency and structural efficiency. It is not obvious, however, whether or not it makes sense to combine these metrics in some fashion to create an "aero-structural efficiency" metric. The approach taken here is to first decide how to define "aero-structural efficiency" and then derive an expression to measure it.

There are many potential ways to view aero-structural efficiency. The focus of this paper will be the concept of aero-structural efficiency as applied to the wing, although it could be extended to the vehicle as a whole as well. Aerostructural efficiency as defined here is based on the premise that the primary job of a wing is to provide lift. An increase in aero-structural efficiency is realized when that lift can be generated at lower drag and/or with a lighter weight wing. There is, of course, a fundamental connection between the impacts that drag and weight have at the overall aircraft system level. The amount of lift an aircraft generates increases the amount of drag generated. The lift generated, in turn, depends on the weight, where lift is equal to weight in steady, straight and level flight. A change in the weight of the wing, therefore, ultimately leads to a change in aircraft drag. It is easy to see conceptually at least, how weight and drag could be combined together into one metric based on their relative impacts on the overall aircraft design.

One possible approach to measure aero-structural efficiency is to develop a metric that considers both drag and weight characteristics in a simple combination. A metric similar to lift-to-drag ratio could be envisioned in which lift is divided by a combination of drag and weight. However, to be useful in comparing aircraft designs, the combination should reflect the differences in sensitivity of the overall vehicle to a pound of weight and a pound of drag. Such a metric could look like: $\mathrm{L} /\left(\mathrm{D}+\mathrm{c} \mathrm{W}_{\text {wing }}\right)$, where $\mathrm{c}$ is a scaling factor to appropriately scale weight impacts to drag impacts.

This approach provides a simple way to quantify aero-structural efficiency, but it has a few shortcomings. For one, the appropriate value for "c" will vary among different aircraft designs. But the biggest issue with this particular metric is that it is an ad-hoc combination of weight and drag without any fundamental theoretical basis behind it. This simple combination is just one example of an ad-hoc metric to combine weight and drag. For example, another possible combination would be a.(L/D) $+b \cdot\left(L / W_{\text {wing }}\right)$. There is no basis for picking one approach over the other. To better establish a basis for the aero-structural efficiency metric, a more fundamental approach is needed rather than an adhoc combination of aircraft characteristics.

\section{A. Concept of "Effective $L / D$ "}

"Effective $\mathrm{L} / \mathrm{D}$ " is a proposed metric to incorporate wing weight characteristics into the traditional $\mathrm{L} / \mathrm{D}$ parameter, so that the trade-off of drag and wing weight can be more explicitly captured. The nature of the trade-off actually varies depending on the overall objective of the design. In other words, the L/D and wing weight trades will be different if the designer's focus is aircraft weight, cost, or fuel consumption. Since reduced fuel consumption is a primary focus of NASA's research activities, the development described here assumes fuel consumption is the aircraft characteristic of interest and the basis for the trades. The basic idea proposed is that a given aircraft's "Effective L/D" is defined to 
be the L/D that returns the same fuel consumption as the original aircraft when the aircraft is redesigned for the same mission with the wing weight reduced to zero. Note that the lower the wing weight is, the less change that is introduced by eliminating wing weight and the closer the effective $\mathrm{L} / \mathrm{D}$ (denoted $\mathrm{L} / \mathrm{D}^{\mathrm{E}}$ here) becomes to the vehicle's normal aerodynamic L/D. For any real vehicle with non-zero wing weight, $\mathrm{L} / \mathrm{D}^{\mathrm{E}}$ will be less than the aerodynamic $\mathrm{L} / \mathrm{D}$, because when the wing weight is eliminated L/D has to be reduced to increase fuel consumption back up to the original value. Two designs for the same mission with the same aerodynamic efficiency but differing wing weights would have different values for $\mathrm{L} / \mathrm{D}^{\mathrm{E}}$. The design with the heavier wing would consume more fuel, and therefore when the wing weight is reduced to zero a larger increase in drag (reduction in L/D) would be necessary to recover the original fuel consumption. Two aircraft with equal $\mathrm{L} / \mathrm{D}^{\mathrm{E}}$ (and propulsion efficiency) designed for the same mission should, in turn, result in approximately the same fuel consumption even though their L/D and wing weights may differ, because $\mathrm{L} / \mathrm{D}^{\mathrm{E}}$ captures the combined impacts of $\mathrm{L} / \mathrm{D}$ and wing weight on fuel consumption.

The concept of $\mathrm{L} / \mathrm{D}^{\mathrm{E}}$ can be seen more clearly in the graphical representations of Figure 1 through Figure 3 . The three curves in Figure 1 show the variation of fuel consumption with start-of-cruise L/D for different levels of wing structural technology. Note that each point along these curves represents a vehicle sized to perform the same design mission (i.e., wing area, engine thrust, and takeoff weight are changing). To generate these curves, variations in drag and weight characteristics were simulated with multiplicative factors applied to a baseline starting point. As shown in Figure 1, a given L/D (aerodynamic efficiency) will lead to different fuel consumption depending on the weight (structural efficiency) of the wing. The "zero wing weight" curve represents the absolute maximum in wing structural efficiency and the datum from which the $\mathrm{L} / \mathrm{D}^{\mathrm{E}}$ parameter is determined. The approach for determining $\mathrm{L} / \mathrm{D}^{\mathrm{E}}$ is illustrated in Figure 1. Consider a vehicle with the L/D and wing weight characteristics corresponding to the star in the figure. The value of $\mathrm{L} / \mathrm{D}^{\mathrm{E}}$ is determined by moving to the left at a constant block fuel to the "zero wing weight" curve and then down to the $\mathrm{L} / \mathrm{D}$ axis, as shown by the dotted lines. That is, the $\mathrm{L} / \mathrm{D}^{\mathrm{E}}$ is the $\mathrm{L} / \mathrm{D}$ that results in the same fuel consumption when wing weight is reduced to zero.

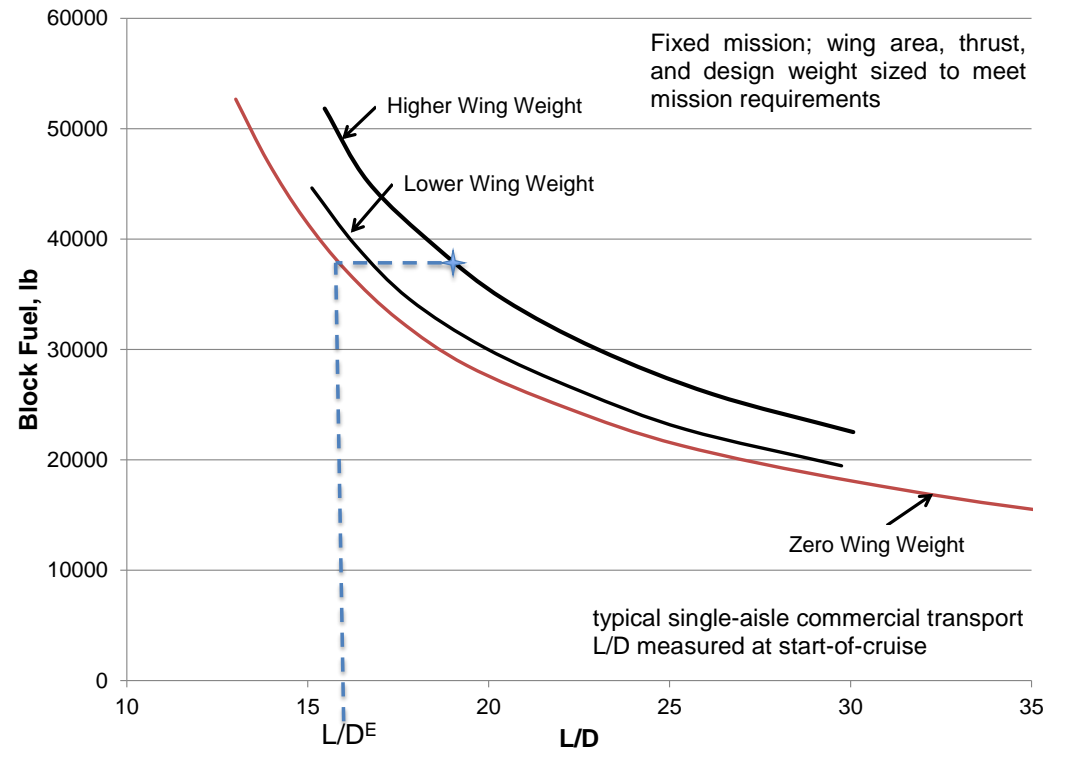

Figure 1. Graphical representation of $L / D^{E}$ calculation based on variation of fuel consumption with $L / D$ and wing weight.

Figure 2 illustrates how the value of the $\mathrm{L} / \mathrm{D}^{\mathrm{E}}$ parameter can be improved by introducing technologies that reduce the wing weight (increase structural efficiency). A lower wing weight moves the design closer to the zero wing weight curve and reduces the difference between $\mathrm{L} / \mathrm{D}$ and $\mathrm{L} / \mathrm{D}^{\mathrm{E}}$. Therefore, even if $\mathrm{L} / \mathrm{D}$ is unchanged, $\mathrm{L} / \mathrm{D}^{\mathrm{E}}$ is improved. In Figure 3, the drag of the airplane is reduced, improving L/D. Because the block fuel versus $\mathrm{L} / \mathrm{D}$ trend curves have similar shapes, when the new $\mathrm{L} / \mathrm{D}$ is converted to $\mathrm{L} / \mathrm{D}^{\mathrm{E}}$ the increase in $\mathrm{L} / \mathrm{D}^{\mathrm{E}}$ is similar to the increase in $\mathrm{L} / \mathrm{D}$. It is clear from these figures that $\mathrm{L} / \mathrm{D}^{\mathrm{E}}$ is sensitive to both improvements in wing structural technology and wing aerodynamic technology, reflecting the idea of wing aero-structural efficiency. 


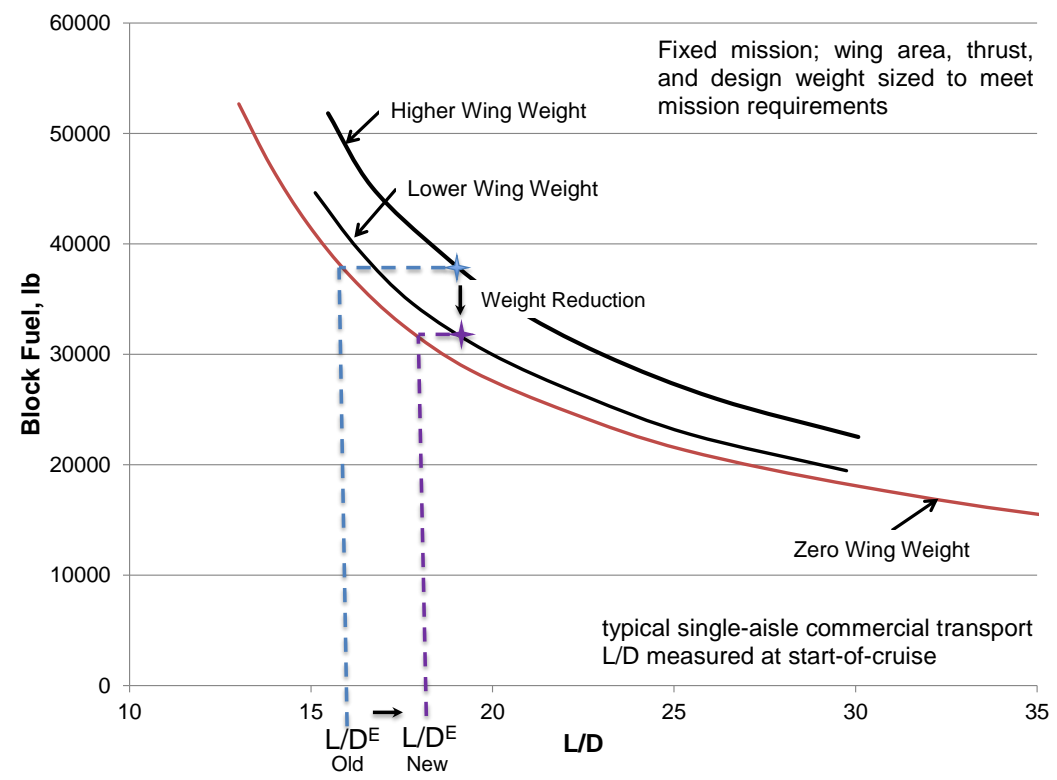

Figure 2. Impact of wing weight reduction on fuel consumption and $L / D^{E}$.

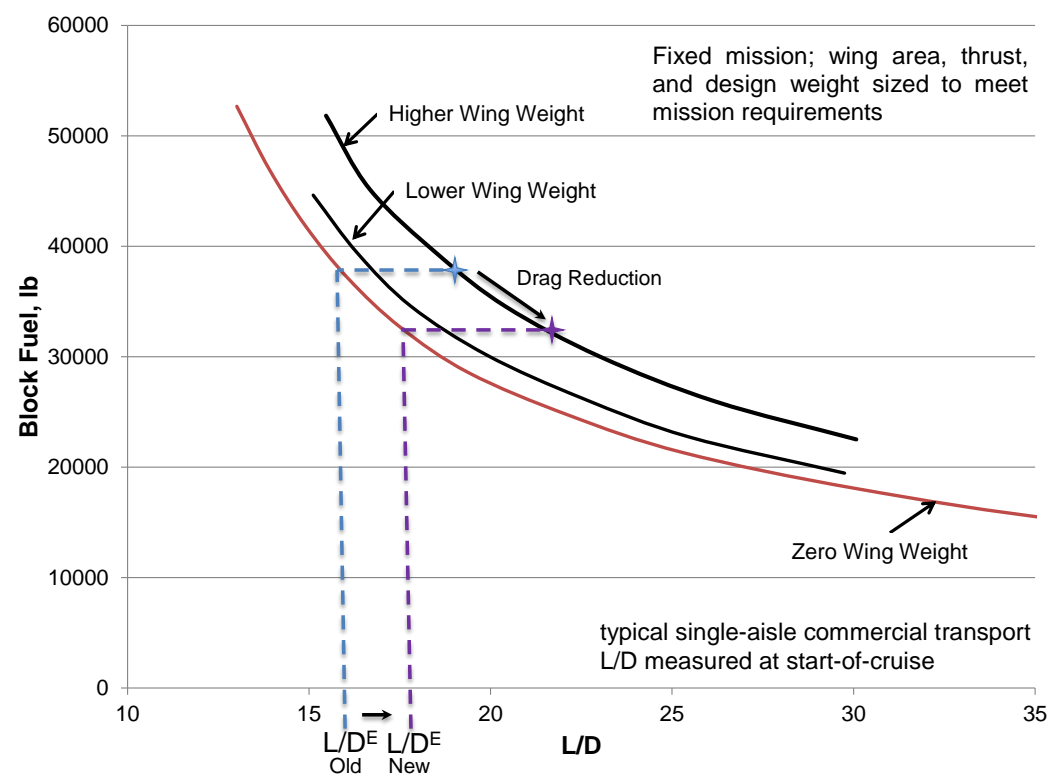

Figure 3. Impact of drag reduction on fuel consumption and $L / D^{E}$.

As a more concrete demonstration of the $\mathrm{L} / \mathrm{D}^{\mathrm{E}}$ concept, the effective $\mathrm{L} / \mathrm{D}$ of a 737-like vehicle was determined through simulation by eliminating the wing weight in the design analysis and iterating on a drag multiplication factor until block fuel increased back to the original value. The resulting L/D with the drag multiplication factor was then calculated. The NASA aircraft design and analysis code, Flight Optimization System (FLOPS), ${ }^{2}$ was used for the simulation. As noted previously, aircraft $\mathrm{L} / \mathrm{D}$ is not a single number so it is necessary to set a specific condition as the basis for $\mathrm{L} / \mathrm{D}$ and $\mathrm{L} / \mathrm{D}^{\mathrm{E}}$. For consistency the same basis should be used for both. Start-of-cruise, end-of-cruise, and average cruise $\mathrm{L} / \mathrm{D}$ are examined in this example. Also, the $\mathrm{L} / \mathrm{D}^{\mathrm{E}}$ result is dependent on the mission for which block fuel is calculated. In this example case, the nominal design mission was used. Various L/D characteristics for this example case are shown in Table 1. For this airplane, $\mathrm{L} / \mathrm{D}^{\mathrm{E}}$ is $11-12 \%$ less than $\mathrm{L} / \mathrm{D}$. 
Table 1. Example Application of Effective L/D Concept using Simulation

\begin{tabular}{|l|c|c|c|}
\hline Target Block Fuel= $\mathbf{3 6 8 0 3} \mathrm{lb}$ & $\begin{array}{c}\text { 737-like Baseline } \\
\text { (L/D) }\end{array}$ & $\begin{array}{c}\text { Zero Wing Weight, } \\
\text { Increased Drag (L/D }\end{array}$ & Ratio \\
\hline Start-of-Cruise & 18.26 & 16.19 & 0.89 \\
\hline End-of-Cruise & 17.84 & 15.68 & 0.88 \\
\hline Mid-Cruise & 18.04 & 16.01 & 0.89 \\
\hline
\end{tabular}

In the above example, the aircraft was resized (wing area, thrust, maximum gross weight) for the same mission requirements at each iteration. Although this makes the determination of $\mathrm{L} / \mathrm{D}^{\mathrm{E}}$ more difficult compared to holding those parameters fixed, doing so is necessary to capture the weight growth factor effects (that is, changing wing weight by one pound changes total weight by more than one pound when mission performance requirements are fixed).

\section{B. Theoretical Formulation of "Effective L/D"}

The simulation-based approach for determining $\mathrm{L} / \mathrm{D}^{\mathrm{E}}$ demonstrated above results in an exact value by definition, assuming an accurate analytical model of the aircraft design. However, this is quite a cumbersome approach to determining the value of a metric. Obviously, it is also not possible to measure $\mathrm{L} / \mathrm{D}^{\mathrm{E}}$ as defined above in flight tests. Therefore, a more practical formulation was explored leveraging the Breguet range equation (Eq. (1)). Even though the Breguet range equation represents an idealized view of aircraft cruise performance, it is, nonetheless, a useful tool for describing the dependencies of cruise performance on weight, aerodynamic efficiency, and propulsion efficiency.

Under the simplifying conditions of constant velocity, constant $L / D$, and constant $T S F C$, aircraft range is given by Eq. (1):

$$
R=\frac{\left(V \cdot \frac{L}{D}\right)}{T S F C} \ln \left(\frac{W_{\text {start }}}{W_{\text {end }}}\right)=-\frac{\left(V \cdot \frac{L}{D}\right)}{T S F C} \ln \left(\frac{W_{\text {end }}}{W_{\text {start }}}\right) .
$$

Consider an idealized aircraft that has all of its fuel consumed in cruise (for the 737-like baseline above, $87 \%$ of the fuel is consumed in cruise). For the idealized, cruise-only aircraft, the weight at start-of-cruise is the takeoff weight, $W_{\text {start }}=W_{T o}$, and the weight at end-of-cruise is, $W_{\text {end }}=W_{T O}-W_{\text {fuel }}$.

$$
R=-\frac{\left(V \cdot \frac{L}{D}\right)}{T S F C} \ln \left(\frac{W_{T O}-W_{\text {fuel }}}{W_{T O}}\right)
$$

This can also be expressed in terms of the fuel fraction, $F_{\text {fuel }}=W_{\text {fuel }} / W_{T O}$ :

$$
R=-\frac{\left(V \cdot \frac{L}{D}\right)}{T S F C} \ln \left(1-F_{\text {fuel }}\right)
$$

Solving the prior range equation for $\mathrm{L} / \mathrm{D}$,

$$
\frac{L}{D}=-\frac{T S F C \cdot R}{V} \cdot \frac{1}{\ln \left(\frac{W_{T O}-W_{\text {fuel }}}{W_{T O}}\right)}
$$


The definition of $\mathrm{L} / \mathrm{D}^{\mathrm{E}}$ involves a comparison of two cases: 1) the performance and characteristics of the actual aircraft, and 2) a fictitious case in which the mission and the fuel consumption are the same but the wing weight is reduced to zero. These two cases are denoted by subscripts 1 and 2 in the following equations. By definition, the L/D for case 2 is $\mathrm{L} / \mathrm{D}^{\mathrm{E}}$.

$$
\left(\frac{L}{D}\right)^{E}=\left(\frac{L}{D}\right)_{2}=-\frac{T S F C_{2} \cdot R_{2}}{V_{2}} \cdot \frac{1}{\ln \left(\frac{W_{T O_{2}}-W_{\text {fuel }_{2}}}{W_{T O_{2}}}\right)}
$$

The primary difference between case 1 and case 2 is the elimination of wing weight. Although there could be some variation in $T S F C$ and $V$ between the two cases, a simplifying assumption is made that $V_{2} \approx V_{1}$ and $T S F C_{2} \approx T S F C_{1}$. By definition, the range and fuel consumption are also the same for both cases. Dropping the subscripts for these invariant terms,

$$
\left(\frac{L}{D}\right)^{E}=-\frac{T S F C \cdot R}{V} \cdot \frac{1}{\ln \left(\frac{W_{T O_{2}}-W_{\text {fuel }}}{W_{T O_{2}}}\right)}
$$

Takeoff weight can be expressed as the sum of operating empty weight ( $\left.W_{\text {OEW }}\right)$, payload weight $\left(W_{\text {pay }}\right)$, and fuel weight ( $\left.W_{\text {fuel }}\right)$. The payload weight and the fuel weight are the same for both cases, such that:

and,

$$
W_{T O_{1}}=W_{\text {pay }}+W_{\text {fuel }}+W_{O E W_{1}}
$$

$$
W_{\mathrm{TO}_{2}}=W_{\text {pay }}+W_{\text {fuel }}+W_{O E W_{2}}
$$

The only difference between the two takeoff weights is in the operating empty weight. For case 2, the wing weight is reduced to zero. In the direct simulation of the 737-like aircraft described in the previous section, the aircraft was allowed to resize after the wing weight was eliminated. This allowed secondary effects on WOEW such as reduced engine size and weight to be captured. However, for this theoretical formulation these secondary effects are ignored and the difference between $W_{O E W_{1}}$ and $W_{O E W_{2}}$ is assumed to be only the weight of the wing, $W_{\text {wing. }}$. With this simplification,

$$
W_{T O_{2}}=W_{T O_{1}}-W_{\text {wing }} .
$$

Substituting this relationship into Eq. (3),

$$
\begin{aligned}
\left(\frac{L}{D}\right)^{E}= & -\frac{T S F C \cdot R}{V} \cdot \frac{1}{\ln \left(\frac{W_{T O_{1}}-W_{\text {wing }}-W_{\text {fuel }}}{W_{T O_{1}}-W_{\text {wing }}}\right)} \\
& \left.=-\frac{T S F C \cdot R}{V} \cdot \frac{1}{\ln \left(\frac{1-\frac{W_{\text {wing }}}{W_{T O_{1}}}-\frac{W_{\text {fuel }}}{W_{T O_{1}}}}{1-\frac{W_{\text {wing }}}{W_{T O_{1}}}}\right)}\right) \\
& =-\frac{T S F C \cdot R}{V} \cdot \frac{1}{\ln \left(\frac{1-F_{\text {wing }}-F_{\text {fuel }}}{1-F_{\text {wing }}}\right)},
\end{aligned}
$$


where $F_{\text {wing }}$ and $F_{\text {fuel }}$ are the wing and fuel weight fractions of the actual aircraft, $W_{\text {wing }} / W_{\text {TO }}$ and $W_{\text {fuel }} / W_{\text {TO }}$. Using the Breguet relationship, the fuel fraction can be expressed as a function of the range, velocity, $L / D$, and TSFC. Starting with Eq. (2) and solving for $F_{f u e l}$,

$$
\begin{gathered}
R=-\frac{\left(V \cdot \frac{L}{D}\right)}{T S F C} \ln \left(1-F_{\text {fuel }}\right) \\
\frac{-R \cdot T S F C}{\left(V \cdot \frac{L}{D}\right)}=\ln \left(1-F_{\text {fuel }}\right) \\
e^{\frac{-R \cdot T S F C}{\left(V \cdot \frac{L}{D}\right)}}=1-F_{\text {fuel }} \\
\frac{-R \cdot T S F C}{\left(V \cdot \frac{L}{D}\right)}-1=-F_{\text {fuel }} \\
1-e^{\frac{-R \cdot T S F C}{\left(V \cdot \frac{L}{D}\right)}}=F_{\text {fuel }}
\end{gathered}
$$

It is convenient to introduce the parameter $\beta$, where

and

$$
\beta=\frac{-R \cdot T S F C}{\left(V \cdot \frac{L}{D}\right)},
$$

Substituting Eq. (5) into Eq. (4),

$$
F_{\text {fuel }}=1-e^{\beta}
$$

$$
\begin{gathered}
\left(\frac{L}{D}\right)^{E}=-\frac{T S F C \cdot R}{V} \cdot \frac{1}{\ln \left(\frac{1-F_{\text {wing }}-1+e^{\beta}}{1-F_{\text {wing }}}\right)} \\
=-\frac{T S F C \cdot R}{V} \cdot \frac{1}{\ln \left(\frac{e^{\beta}-F_{\text {wing }}}{1-F_{\text {wing }}}\right)}
\end{gathered}
$$

Finally, substituting $\beta\left(\frac{L}{D}\right)$ for $\left(-\frac{T S F C \cdot R}{V}\right)$ results in:

$$
\left(\frac{L}{D}\right)^{E}=\frac{L}{D} \cdot \frac{\beta}{\ln \left(\frac{e^{\beta}-F_{\text {wing }}}{1-F_{\text {wing }}}\right)}
$$

Even though Eq. (6) was derived for a simplified, idealized aircraft, it can still be applied to more realistic scenarios. Referring back to Eq. (1), it can be shown that $\beta=\ln \left(W_{\text {end }} / W_{\text {start }}\right)$ for a Breguet cruise. For an actual aircraft mission, where $L / D, T S F C$, and $V$ may be changing throughout the flight and the mission includes more than just a cruise segment, this equation can be applied to the overall mission and the $\beta$ parameter can be considered an effective value to represent the entire mission as a Breguet cruise. Even though Eq. (6) looks like a complicated expression for an aero-structural efficiency metric, with this expression L/D can be converted to $L / D^{\mathrm{E}}$ using only takeoff weight, wing weight, and fuel weight. 


\section{Simplified Expression for $L / D^{\mathrm{E}}$}

Although Eq. (6) provides a theoretical basis for the calculation of the $\mathrm{L} / \mathrm{D}^{\mathrm{E}}$ parameter, it is not an easily explained and interpreted relationship. In order to examine the behavior of this metric more closely, a series of test cases were developed using the idealized aircraft model defined above and varying $F_{\text {wing, }} L / D, T S F C, R$, and $V$. A polynomial response surface was fitted to the calculated $\mathrm{L} / \mathrm{D}^{\mathrm{E}}$ values from which it was determined that Eq. (6) can be approximated by:

$$
\left(\frac{L}{D}\right)^{E}=\frac{L}{D} \cdot\left(1-F_{\text {wing }}\right) .
$$

This provides a simpler expression for $\mathrm{L} / \mathrm{D}^{\mathrm{E}}$ at the expense of accuracy. In particular, note that this expression is insensitive to the parameters that determine $\beta$. However, as $\beta$ approaches zero (implying fuel fraction goes to zero), the result of Eq. (6) approaches the result of Eq. (7). Matching the exact value of $\mathrm{L} / \mathrm{D}^{\mathrm{E}}$ from Eq. (6) may not be particularly important given the simplifying assumptions inherent in its derivation. What is noteworthy, however, is that the relationship in Eq. (7) shows the concept of aero-structural efficiency can be expressed with a simple metric that combines L/D and $F_{\text {wing. }}$. Unlike the ad-hoc adjustments to L/D shown previously, this expression was derived from a theoretical relationship between $\mathrm{L} / \mathrm{D}$, wing weight, and fuel consumption.

\section{Testing of the $L / D^{E}$ metric}

Three different ways to determine $\mathrm{L} / \mathrm{D}^{\mathrm{E}}$ are summarized in Table 2: simulation, theoretical expression, and simplified expression. Note that, as mentioned previously, a specific flight condition must be defined to obtain a unique value of $\mathrm{L} / \mathrm{D}$ or $\mathrm{L} / \mathrm{D}^{\mathrm{E}}$. A series of test cases have been used to assess the accuracy and effectiveness of the $\mathrm{L} / \mathrm{D}^{\mathrm{E}}$ expressions. The question of accuracy can be stated as how well the two analytical expressions for $\mathrm{L} / \mathrm{D}^{\mathrm{E}}$ match the value obtained from direct simulation. The effectiveness of the $\mathrm{L} / \mathrm{D}^{\mathrm{E}}$ metric is determined by the degree to which it captures the fuel efficiency impacts of the trade-off between drag and wing weight. In other words, do two vehicles with differing $\mathrm{L} / \mathrm{D}$ and wing weight characteristics, but the same $\mathrm{L} / \mathrm{D}^{\mathrm{E}}$ and propulsion efficiency, have similar fuel consumption characteristics?

Table 2. Methods for Determining $L / D^{E}$

\begin{tabular}{|c|l|l|}
\hline Approach & Required Data & Approximation \\
\hline Simulation & $\begin{array}{l}\text { A complete aircraft sizing and } \\
\text { performance model }\end{array}$ & $\begin{array}{l}\text { Exact for the models, approximate } \\
\text { to reality }\end{array}$ \\
\hline $\begin{array}{c}\text { Theoretical Expression } \\
\text { (Equation 6) }\end{array}$ & $\begin{array}{l}\text { L/D plus fuel fraction and wing } \\
\text { weight fraction (or takeoff weight, } \\
\text { wing weight, and fuel weight) }\end{array}$ & $\begin{array}{l}\text { Aircraft characteristics } \\
\text { approximated by "effective" } \\
\text { idealized Breguet cruise model }\end{array}$ \\
\hline $\begin{array}{c}\text { Simplified Expression } \\
\text { (Equation 7) }\end{array}$ & $\begin{array}{l}\text { L/D plus wing weight fraction (or } \\
\text { takeoff weight and wing weight) }\end{array}$ & $\begin{array}{l}\text { Only a function of wing weight } \\
\text { fraction, insensitive to fuel fraction }\end{array}$ \\
\hline
\end{tabular}

\section{Accuracy Tests}

The accuracy of the $\mathrm{L} / \mathrm{D}^{\mathrm{E}}$ expressions has been tested using NASA-developed analytical models of conventional and unconventional aircraft configurations. Analytical models of aircraft provide the ability to simply zero-out the wing weight term and determine a simulation-based value for the $\mathrm{L} / \mathrm{D}^{\mathrm{E}}$ parameter. The results of the expressions (which use measureable characteristics of aircraft) were compared to the simulation-based values to assess the ability to estimate $\mathrm{L} / \mathrm{D}^{\mathrm{E}}$ using measureable parameters.

The first case used to test accuracy is the previously described 737-like model. The simulation-based results for $\mathrm{L} / \mathrm{D}$ and $\mathrm{L} / \mathrm{D}^{\mathrm{E}}$ were shown in Table $1 . F_{\text {wing }}$ for this design is 0.099 . The weight at the end of the flight is $133704 \mathrm{lb}$ $\left(W_{\text {end }}\right)$ and the weight at the start of flight is $170506 \mathrm{lb}\left(W_{\text {start }}\right)$, leading to a calculated effective $\beta$ of -0.243 . Using the values of $\mathrm{L} / \mathrm{D}$ from Table 1, Eqs. (6) and (7) result in the $\mathrm{L} / \mathrm{D}^{\mathrm{E}}$ values listed in Table 3 . As can be seen in the table, the analytical expressions provide good estimates for the simulation-based $\mathrm{L} / \mathrm{D}^{\mathrm{E}}$. The error using the theoretical expression, Eq. (6), is around 1\% whereas the error for the simplified expression, Eq. (7), is around $2 \%$. 
Table 3. Example Application of Approximate Equations for $L / D^{E}$

\begin{tabular}{|l|c|c|c|c|}
\hline & $\begin{array}{c}737-\text {-like Baseline } \\
(\mathrm{L} / \mathrm{D})\end{array}$ & $\begin{array}{c}\text { Simulation-Based L/D } \\
\text { (Table } 1)\end{array}$ & $\begin{array}{c}\mathrm{L} / \mathrm{D}^{\mathrm{E}} \text { from Eq. (6) } \\
\left(\mathrm{F}_{\text {wing }} \text { and effective } \beta\right)\end{array}$ & $\begin{array}{c}\mathrm{L} / \mathrm{D}^{\mathrm{E}} \text { from Eq. (7) } \\
\left(\mathrm{F}_{\text {wing }} \text { only) }\right.\end{array}$ \\
\hline Start-of-Cruise & 18.26 & 16.19 & $16.21(0.1 \%$ error $)$ & 16.45 (1.6\% error) \\
\hline End-of-Cruise & 17.84 & 15.68 & $15.84(1.0 \%$ error $)$ & 16.07 (2.5\% error) \\
\hline Mid-Cruise & 18.04 & 16.01 & $16.02(0.1 \%$ error $)$ & 16.25 (1.5\% error) \\
\hline
\end{tabular}

For the second test case, the analytical expressions were applied to a 777-like aircraft model flying a design range of $7500 \mathrm{~nm}$. The simulation-based value for $\mathrm{L} / \mathrm{D}^{\mathrm{E}}$ (at start-of-cruise) is 16.05 , compared to an $\mathrm{L} / \mathrm{D}$ of 19.06 . The effective $\beta$ for this vehicle is -0.452 and the wing weight fraction is 0.108 . Note that the value of $\beta$ is significantly higher for this design as a result of the large fuel fraction (36\%) for the $7500 \mathrm{~nm}$ mission. Calculating L/D $\mathrm{D}^{\mathrm{E}}$ with Eq. (6) results in a value of $16.46,2.5 \%$ higher than the simulation value. With Eq. (7), $\mathrm{L} / \mathrm{D}^{\mathrm{E}}$ is $17.01,6 \%$ higher than the simulation-based value. In this case, the simplified expression based solely on wing weight fraction does not perform particularly well. It is actually not surprising that the additional dependencies captured with the $\beta$ terms in Eq. (6) are important for a long range aircraft such as the 777. As noted previously, as the fuel fraction goes to zero, the results for the two expressions are the same. For long range aircraft with higher fuel fraction, there is a larger discrepancy in the two expressions.

To assess the accuracy on a more advanced vehicle, the relationships were tested using a NASA model of Boeing's "Refined SUGAR" concept. ${ }^{3}$ Although a conventional configuration, Refined SUGAR incorporates advanced aerodynamic, structural, and propulsion technologies. On the $3500 \mathrm{~nm}$ design mission, the effective $\beta$ is $-0.189, \mathrm{~L} / \mathrm{D}$ at start-of-cruise is 22.11 and $F_{\text {wing }}$ is 0.103 . The simulation-based value for $\mathrm{L} / \mathrm{D}^{\mathrm{E}}$ (at start-of-cruise) is 19.43 . The result of Eq. (6) is $19.60(+0.9 \%)$ and the result of Eq. (7) is $19.83(+2.1 \%)$. The accuracies of the analytical expressions relative to the simulation are similar to those of the 737-like test case.

For a fourth test of the accuracy of the $\mathrm{L} / \mathrm{D}^{\mathrm{E}}$ expressions, the method was applied to the $\mathrm{N} 3-\mathrm{X}$, an unconventional, 777-class, advanced vehicle with aggressive technology assumptions. ${ }^{4}$ For this hybrid wing body vehicle, it is not completely obvious what constitutes "wing weight." However, for consistency the weight that is zeroed out for the simulation-based $\mathrm{L} / \mathrm{D}^{\mathrm{E}}$ approach is the weight used to calculate $F_{\text {wing. }}$. Using the simulation approach, the $\mathrm{L} / \mathrm{D}^{\mathrm{E}}$ of the $\mathrm{N} 3-\mathrm{X}$ was determined to be 24.68 . The result from Eq. (6) is 24.77 ( $0.4 \%$ higher) and the result from Eq. (7) is 24.95 ( $1 \%$ higher). Note that although the $\mathrm{N} 3-\mathrm{X}$ has a long range mission like the 777 , the aggressive advanced technology assumptions result in a relatively low fuel fraction of only 0.15 . In that respect it is similar to the shorter range 737 class aircraft for which the equations were also in good agreement with the simulation-based result.

Table 4 summarizes the results of the four accuracy test cases. Four test cases are not enough to fully assess the ability of the analytical expressions for $\mathrm{L} / \mathrm{D}^{\mathrm{E}}$ to represent the complexities of the "zero wing weight" simulation results. However, the good agreement shown in Table 4 across different vehicle sizes and levels of technology, especially for Eq. (6), is encouraging. Note also that in all four cases the expressions in Eqs. (6) and (7) returned a value of L/D that was higher than the simulation-based result. This is likely a consequence of the simplifying assumptions in the derivation, particularly the assumption that the only change in empty weight for the "zero wing weight" case is the elimination of the wing weight. This assumption reduces the sensitivity of fuel consumption to wing weight, leading to $\mathrm{L} / \mathrm{D}^{\mathrm{E}}$ values that are higher than those obtained by the simulation method in which the full sizing effects on empty weight are captured. 
Table 4. Summary of Results for Accuracy Tests

\begin{tabular}{|c|c|c|c|c|}
\hline & $\begin{array}{l}\text { Start-of-Cruise } \\
\text { L/D }\end{array}$ & Simulation-Based L/D ${ }^{\mathrm{E}}$ & $\begin{array}{c}\mathrm{L} / \mathrm{D}^{\mathrm{E}} \text { from Eq. }(6) \\
\left(\mathrm{F}_{\text {wing }} \text { and effective } \beta\right)\end{array}$ & $\begin{array}{c}\text { L/D } \mathrm{D}^{\mathrm{E}} \text { from Eq. }(7) \\
\left(\mathrm{F}_{\text {wing }} \text { only }\right)\end{array}$ \\
\hline 737-like Model & 18.26 & 16.19 & $16.21(0.1 \%$ error $)$ & 16.45 (1.6\% error) \\
\hline 777-like Model & 19.06 & 16.05 & 16.46 (2.5\% error) & 17.01 (6.0\% error) \\
\hline $\begin{array}{l}\text { Refined SUGAR } \\
\text { Model }\end{array}$ & 22.11 & 19.43 & 19.60 ( $0.9 \%$ error $)$ & 19.83 (2.1\% error) \\
\hline N3-X Model & 27.03 & 24.68 & $24.77(0.4 \%$ error $)$ & 24.95 ( $1.1 \%$ error $)$ \\
\hline
\end{tabular}

\section{Effectiveness Tests}

The next series of test cases were designed to assess the effectiveness of $\mathrm{L} / \mathrm{D}^{\mathrm{E}}$ in capturing general wing weight and vehicle drag technology trades in the context of fuel consumption. A baseline 737-like configuration was modified through a series of wing weight and vehicle drag technology multiplication factors $(-40 \%$ to $+20 \%$ on drag and $-50 \%$ to $+40 \%$ on wing weight). (Note that for each case the design is resized (thrust, wing area, and takeoff weight) to complete the same design mission. L/D is measured at start-of-cruise.) Figure 4 is a plot of fuel consumption versus $\mathrm{L} / \mathrm{D}$ for the matrix of cases. The spread between the two curves indicates the variation in block fuel at a given L/D associated with wing weight characteristics. The effectiveness of the $\mathrm{L} / \mathrm{D}^{\mathrm{E}}$ metric can be assessed by examining how well the data collapses to a single curve when $\mathrm{L} / \mathrm{D}$ is replaced with $\mathrm{L} / \mathrm{D}^{\mathrm{E}}$. If the $\mathrm{L} / \mathrm{D}^{\mathrm{E}}$ metric was perfect in capturing the fuel consumption impacts of both drag and wing weight, all of the cases would collapse to a single curve. In particular, the cases should collapse to the curve that results when wing weight is set to zero and only the drag technology factor is varied, since $\mathrm{L} / \mathrm{D}$ and $\mathrm{L} / \mathrm{D}^{\mathrm{E}}$ are equal in this case. Ideally, $\mathrm{L} / \mathrm{D}^{\mathrm{E}}$ would be determined by simulation for the effectiveness test cases. However, the simulation method is too cumbersome for determining $\mathrm{L} / \mathrm{D}^{\mathrm{E}}$ for a large number of cases. Instead, the analytical expressions in Eq. (6) and (7) were used. As shown in Figure 5, the correlation is very good, but not perfect, for this series of test cases. Deviations from the zero wing weight curve are highest for combinations of low drag and high wing weight. Using the full theoretical expression for $\mathrm{L} / \mathrm{D}^{\mathrm{E}}$ provides a slightly better correlation at the expense of a more complicated expression. Although not perfect, the ability of the L/D ${ }^{\mathrm{E}}$ expressions to simultaneously capture the fuel consumption impacts of aerodynamic efficiency and wing weight is excellent, especially in light of the simplifying assumptions inherent in the derivation from the Breguet equation. 


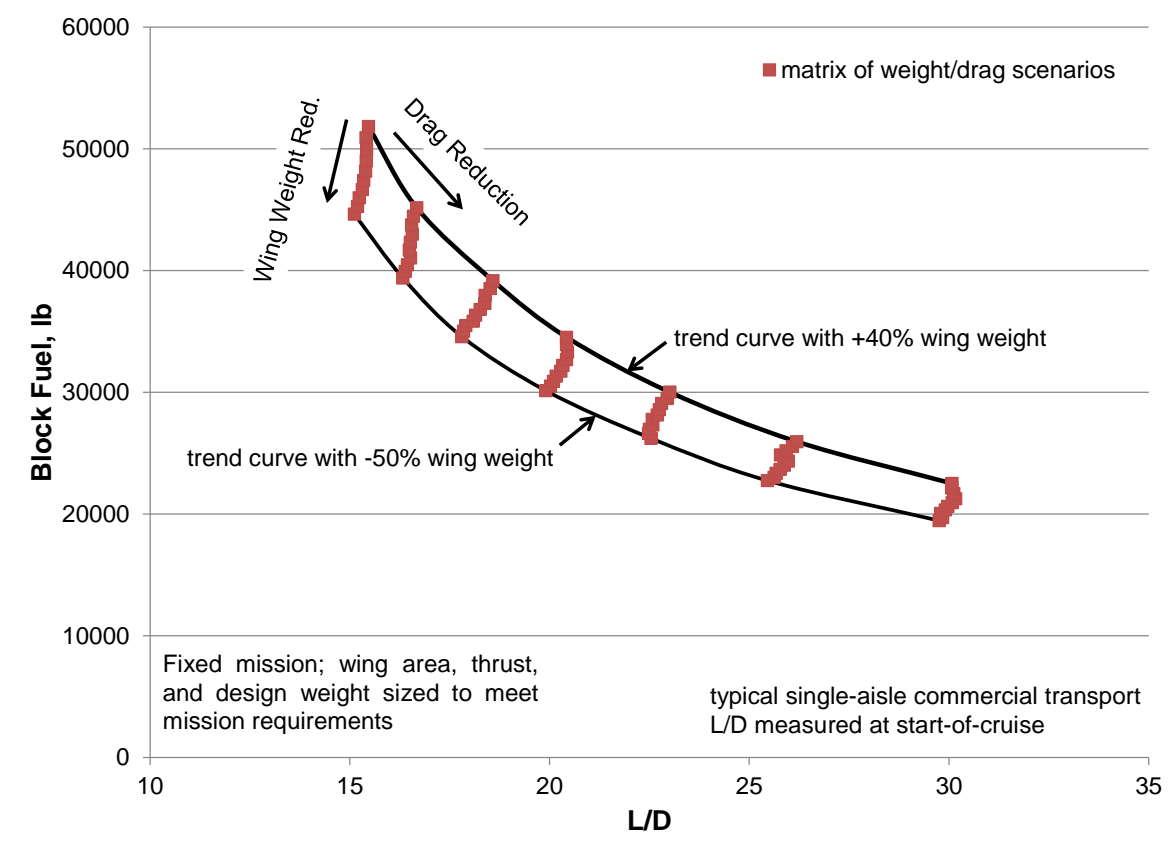

Figure 4. Block fuel as a function of $L / D$ for matrix of wing weight and drag scenarios applied to 737-class aircraft.

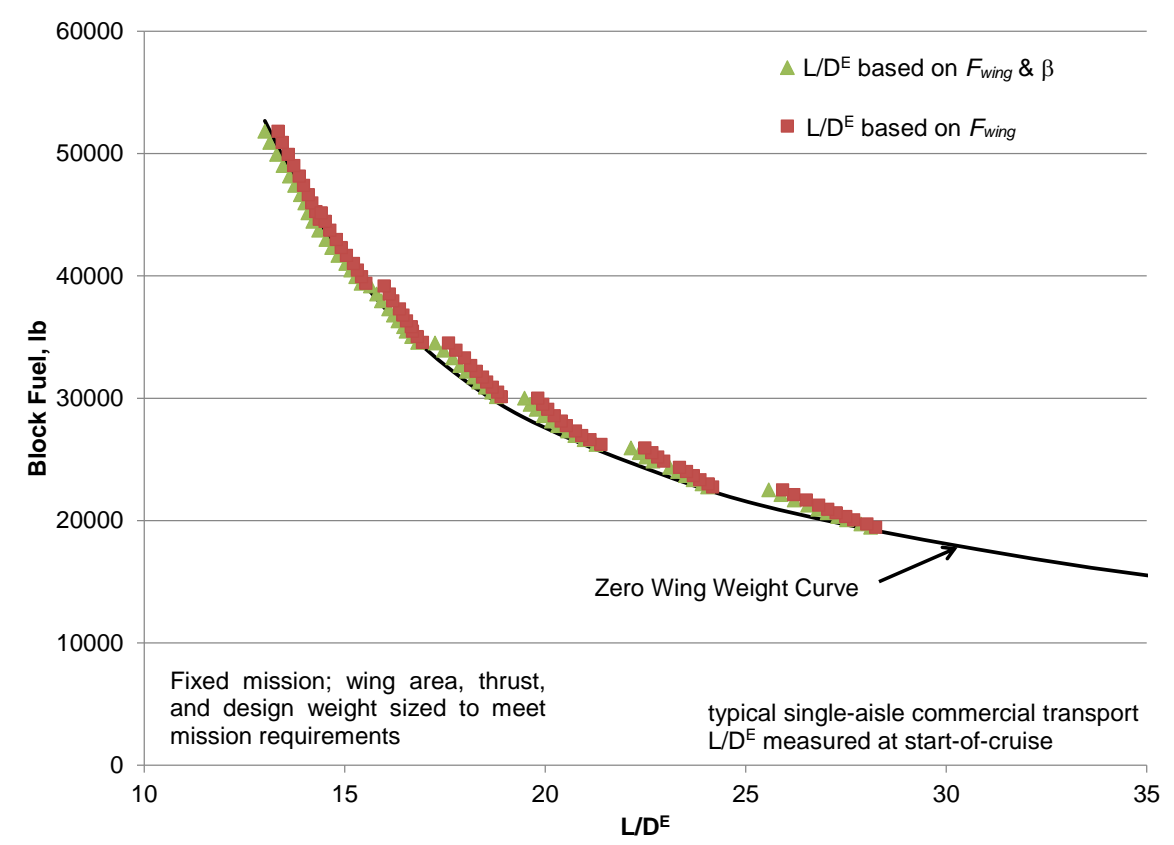

Figure 5. Effectiveness of $\mathrm{L} / \mathrm{D}^{\mathrm{E}}$ in predicting fuel consumption impacts of drag and wing weight trades.

\section{Application of Aero-Structural Efficiency and $L / D^{\mathrm{E}}$ Metric}

The original motivation for this investigation was the need to simply and effectively communicate the combined weight and drag impacts of wing span (or aspect ratio) design choices on aircraft fuel efficiency in order to help guide technology investments. NASA-sponsored studies of "N+3" aircraft (aircraft envisioned three generations beyond today) have pointed toward higher aspect ratio wing designs. ${ }^{3,5,6,7}$ However, higher aspect ratio is not necessarily a good thing even if it improves aerodynamic efficiency. It is only when aero-structural efficiency is increased that 
higher aspect ratio is beneficial. An exclusive focus on aerodynamic efficiency when considering aspect ratio could lead to a poor aircraft design. Reference 8 provides an example of what can happen when focused on aerodynamic efficiency alone. This reference describes a wing optimization study comparing cantilever, strut-braced, and trussbraced wing architectures. Optimum designs were obtained for minimum takeoff weight, minimum fuel weight, and maximum $\mathrm{L} / \mathrm{D}$. The result of designing to maximize $\mathrm{L} / \mathrm{D}$ was an aircraft that was heavier and used more fuel than the other designs, due to the extremely heavy wing designs that resulted. The optimum wing designs in Ref. 8 also include a couple of interesting cases with the same cruise L/D. One design is a truss-braced wing optimized for minimum takeoff weight with an aspect ratio of 17 and cruise L/D of 32. The second is a cantilever design optimized for minimum fuel with an aspect ratio of 15 , which also has a cruise $\mathrm{L} / \mathrm{D}$ of 32 . Looking at $\mathrm{L} / \mathrm{D}$ alone, it is not obvious which design is more fuel efficient. However, $\mathrm{L} / \mathrm{D}^{\mathrm{E}}$ for the first design is 26.6 compared to 23.1 for the second design. The $15 \%$ higher $\mathrm{L} / \mathrm{D}^{\mathrm{E}}$ for the truss-braced wing design is quite consistent with the $16 \%$ lower fuel consumption compared to the cantilever design.

In the past it has been difficult to express the importance of the wing weight and aerodynamic efficiency trades in a simply way. Although the drag-weight trade-offs may be well understood by the aircraft designer, it is often difficult to express these to the aerodynamicist or structural engineer. By focusing on aero-structural efficiency rather than improved L/D or reduced weight, a better mutual understanding of the design needs can be realized. For example, the $\mathrm{L} / \mathrm{D}^{\mathrm{E}}$ expression in Eq. (7) indicates that nominally it is necessary for the improvement in L/D obtained from increasing span to be greater than the decrease in $\left(1-F_{\text {wing }}\right)$ for the change to be beneficial from a fuel efficiency standpoint. This is not an exact result, of course, but it can help guide design choices. This trade can also be expressed in a contour plot to provide design guidance, as shown in Figure 6. This kind of chart enables the amount of weight growth permissible in pursuit of aerodynamic improvements to be readily communicated. The primary value, therefore, of the concept of aero-structural efficiency and the $\mathrm{L} / \mathrm{D}^{\mathrm{E}}$ metric is as a communication tool.

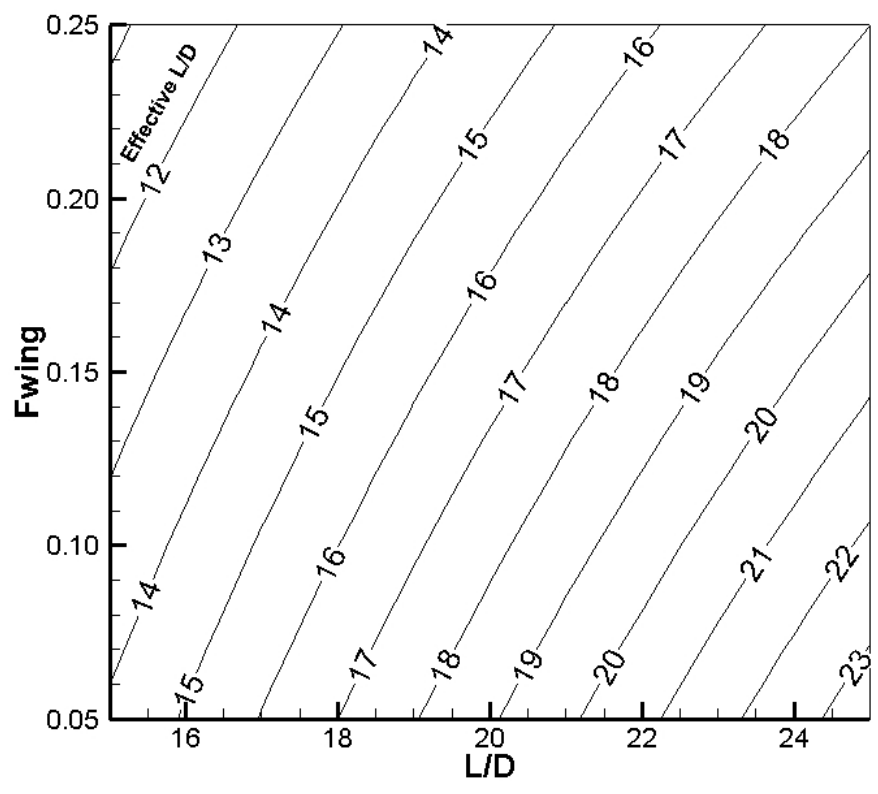

Figure 6. Contours of Effective L/D.

\section{Summary}

One of the many trade-offs that must be considered in aircraft design is the trade between drag and wing weight. The concept of using aero-structural efficiency and effective L/D as a way to measure this trade-off has been presented. The $\mathrm{L} / \mathrm{D}^{\mathrm{E}}$ metric puts drag and weight on an equal footing and enables one to track the fuel efficiency impacts of changes to wing design and technology in a comprehensive manner. Unlike simply tracking improvements in L/D, which may come at the expense of higher weight and could actually lead to greater fuel consumption, improvements in $\mathrm{L} / \mathrm{D}^{\mathrm{E}}$ correlate with improvements in fuel consumption. The $\mathrm{L} / \mathrm{D}^{\mathrm{E}}$ parameter is defined based on simulation of the fictitious situation of a zero weight wing. However, a theoretical expression has been derived based on an idealized aircraft performance model using the Breguet range equation. This theoretical expression for $\mathrm{L} / \mathrm{D}^{\mathrm{E}}$ can be used to 
adjust $\mathrm{L} / \mathrm{D}$ of real aircraft with knowledge of only the takeoff weight, fuel weight, and wing weight. $\mathrm{L} / \mathrm{D}^{\mathrm{E}}$ can be further simplified to an approximate expression based solely on wing weight fraction. The analytical expressions for $\mathrm{L} / \mathrm{D}^{\mathrm{E}}$ have been found to agree well with values determined using simulation of aircraft sizing and performance. The $\mathrm{L} / \mathrm{D}^{\mathrm{E}}$ parameter has also been found to be effective in capturing the trade-off between wing weight and aerodynamic efficiency, with good correlation between fuel consumption and $\mathrm{L} / \mathrm{D}^{\mathrm{E}}$ for various combinations of drag and wing weight. Although applied to drag and wing weight in this particular instance, the approach taken in this paper could also potentially be applied to other weight trade-offs in aircraft design. For example, an "effective TSFC" could be defined that encompasses both the engine weight and propulsion efficiency. Future studies should examine the utility of this approach in other areas of aircraft design.

\section{References}

${ }^{1}$ Raymer, D. P., Aircraft Design: A Conceptual Approach, $2^{\text {nd }}$ ed., AIAA Education Series, AIAA, Washington, DC, 1992, pp. 459-461.

${ }^{2}$ McCullers, L., "Aircraft Configuration Optimization Including Optimized Flight Profiles," Proceedings of the Symposium on Recent Experiences in Multidisciplinary Analysis and Optimization, NASA CP-2327, 1984.

${ }^{3}$ Bradley, M. K., and Droney, C. K., "Subsonic Ultra Green Aircraft Research Phase I Final Report,” NASA/CR-2011-216847, April 2011.

${ }^{4}$ Kim, H. D., et al., "Turboelectric distributed propulsion benefits on the N3-X vehicle," Aircraft Engineering and Aerospace Technology: An International Journal, Vol. 86, Issue 6, pp. 558-561.

${ }^{5}$ Greitzer, E. M., et al., "N+3 Aircraft Concept Designs and Trade Studies, Final Report,” NASA/CR-2010-216794, December 2010.

${ }^{6}$ Bruner, S., et al., "NASA N+3 Subsonic Fixed Wing Silent Efficient Low-Emissions Commercial Transport (SELECT) Vehicle Study," NASAICR-2010-216798, November 2010.

${ }^{7}$ D'Angelo, M. M., et al., "N+3 Small Commercial Efficient and Quiet Transportation for Year 2030-2035," NASA/CR-2010216691, May 2010.

${ }^{8}$ Gur, O., et al., "Design Optimization of a Truss-Braced Wing Aircraft,” AIAA 2009-7114, September 2009. 